Brit. J. industr. Med., 1964, 21, 117.

\title{
A COMPARISON OF POLYCYCLIC AROMATIC HYDRO- CARBON EMISSIONS FROM DIESEL- AND PETROL-POWERED VEHICLES IN PARTIALLY SEGREGATED TRAFFIC LANES
}

\author{
BY \\ J. L. SULLIVAN and G. J. CLEARY \\ From the Air Pollution Control Branch, N.S.W. Department of Public Health, Sydney, and \\ the School of Chemical Technology, University of New South Wales, Sydney, Australia
}

(RECEIVED FOR PUBLICATION MARCH 18, 1963)

\begin{abstract}
As the result of special traffic conditions at a point in Sydney, diesel-powered vehicles are partially segregated in one of 10 road lanes during the peak evening period. Because of this, it was found possible to sample simultaneously in two of the road lanes, about 40 feet apart, only one of which was carrying diesel vehicles. For approximately one month samples were collected for part of the evening traffic peak period and were then pooled and analysed for polycyclic aromatic hydrocarbons. Because it was also necessary for vehicles to stop briefly, all were accelerating past the sampling point. An association was established between traffic containing diesel vehicles and the concentrations of smoke, 1,2-benzpyrene, 3,4-benzpyrene, 1,12-benzperylene, and coronene.
\end{abstract}

Recent investigations of the contribution to air pollution by polycyclic aromatic hydrocarbons from diesel-powered vehicles have tended to show inconsistent results. In studies by Kotin, Falk, and Thomas (1955), it was shown that significant quantities of 3,4-benzpyrene and other hydrocarbons were emitted from a stationary diesel engine operated under simulated load conditions. The actual quantity of polycyclic hydrocarbons emitted depended largely on factors such as engine adjustment and load condition, and the range of values reported for 3,4-benzpyrene varied from zero for a wellmaintained engine under normal load to $1706 \mu \mathrm{g}$./ min. for a badly adjusted engine operating under heavy load.

Subsequent studies by Commins, Waller, and Lawther (1957) inside a London omnibus garage, and by Moore and Katz (1960) in railway tunnels in Canada, revealed that concentrations of benzpyrene in the working atmosphere in which actual diesel vehicles were operating were of an order similar to that of the ambient atmosphere in each case. From both of these studies it was possible to conclude that diesel vehicles, presumably well maintained, made a negligible contribution to polycyclic hydrocarbon pollution. However, more recent studies by Waller, Commins, and Lawther (1961) in London road tunnels showed that concentrations of polycyclic hydrocarbons tended to be higher than average atmospheric values, and that pyrene, fluoranthene, 1,2-benzpyrene, and 3,4benzpyrene concentrations as well as smoke density tended to be more closely related to the density of diesel- rather than petrol-powered vehicles.

The present paper reports observations made in the City of Sydney, New South Wales, at a location where it was possible to make a reasonably good separation between diesel and petrol vehicles. Because of a specific traffic requirement at a particular period of the day diesel vehicles which pass one specific point must decelerate very considerably and sometimes stop briefly. Motor-cars also stop at this same point, but there is another similar location about 10 to 12 yards from the first which is not used by diesel vehicles at all. Because of the necessity to pay toll, petrol-burning motor-cars stop briefly and then pass on. The diesel vehicles referred to do not pay toll but they are usually caused to slow down because of the accumulation of cars. The result of the study supported the findings of Waller et al. (1961) in that the emission of polycyclic hydrocarbons varies according to the number of diesel 
rather than petrol vehicles, although in our case this trend was only noticeable with higher molecular weight compounds, which included 3,4-benzpyrene.

\section{Description of Sampling Area and Vehicle Data}

The samples which were collected in this series and subsequently analysed for polycyclic hydrocarbons were obtained at a point on one of Sydney's major highways where, at the afternoon traffic peak period, an almost complete segregation of diesel vehicles was seen to occur regularly. This happens in Sydney because vehicular traffic leaving the city divides into well-defined lanes, only one of which is used by diesel vehicles at the afternoon traffic peak. Thus it was possible to sample concurrently adjacent to this lane and to another lane 40 feet away, which was used only by motor-cars. However, the lane used by diesel vehicles also carried petrolburning motor-cars, and consequently the separation could not be regarded as complete. Table 1 gives a comparison between the vehicles travelling in the two lanes as well as the dates and times of collecting samples. As far as possible, sampling in the two lanes was simultaneous, but slight differences occurred as the result of the time taken to install and dismantle the instruments and to change the filter pads. All samples collected during the period were subsequently pooled for analysis.

As the quantities of polycyclic hydrocarbons could be expected to be proportional to the volumes of exhaust gases emitted, sample counts of vehicle types were made. In Australia the most popular motor-car type has an engine volume of about $2,250 \mathrm{cc}$., but there are small numbers of larger and smaller models. The latter are somewhat more numerous than the former, and the average swept volume was estimated to be approximately $2,000 \mathrm{cc}$., which was the value taken in this survey. As the diesel vehicles fell into a smaller number of engine classes, ranging between 8,400 and $11,100 \mathrm{cc}$., it was possible to obtain a reasonably accurate assessment of the mean engine volume. Based on an actual frequency estimate, a mean volume of 10,000 cc. per vehicle was thus obtained.

In view of the relatively close proximity of the two sampling points, wind direction and velocity readings were made continuously during the study. Winds from a direction which could have caused contaminants to be blown from the diesel lane to the petrol vehicle lane occurred for approximately $14 \%$ of the time at a mean velocity of 8 knots. Generally wind velocities at the sampling points tended to vary between 5 and 10 knots on most afternoons of the survey. At the points where the samples were collected the vehicles were moving up a very slight incline.

\section{Sampling and Analytical Procedures}

Sampling was conducted at three points simultaneously. The first was in the lane used by motor-cars only, the second in the lane carrying diesel vehicles as well as cars, and a third point was 300 yards away from general traffic concentrations but in the same general atmosphere as the first two. The last mentioned was considered normal background for the city. All vehicles passing the sampling point were accelerating because of the necessity to stop or slow down and were moving at about 10 miles per hour.

Air particulate samples at the three locations were obtained by passing 20 to 50 cubic feet of air per minute through M.S.A. and Staplex high volume samplers fitted with fibre-glass filter pads. Samples were taken during the evening peak hour each day between 4.30 p.m. and 6.30 p.m.

The sample pads were extracted for about five hours with acetone in a soxhlet apparatus, the actual time being

TABLE 1

DETAILS OF VEHICLES PASSING THE TWO ROAD TEST POINTS

\begin{tabular}{|c|c|c|c|c|c|c|c|c|c|c|}
\hline \multirow{3}{*}{ Date (1962) } & \multicolumn{5}{|c|}{ Petrol Vehicle Sampling Site } & \multicolumn{5}{|c|}{ Diesel Vehicle Sampling Site } \\
\hline & \multirow{2}{*}{ Cars } & \multirow{2}{*}{ Diesels } & \multicolumn{2}{|c|}{ Sampler } & \multirow{2}{*}{$\begin{array}{c}\text { Sampling } \\
\text { Time (min.) }\end{array}$} & \multirow{2}{*}{ Cars } & \multirow{2}{*}{ Diesels } & \multicolumn{2}{|c|}{ Sampler } & \multirow{2}{*}{$\begin{array}{l}\text { Sampling } \\
\text { Time (min.) }\end{array}$} \\
\hline & & & On (p.m.) & Off (p.m.) & & & & On (p.m.) & Off (p.m.) & \\
\hline $\begin{array}{l}\text { March } 12 \\
\text { March } 13 \\
\text { March } 14 \\
\text { March } 16 \\
\text { March } 19 \\
\text { March } 20 \\
\text { March } 21 \\
\text { March } 22 \\
\text { March } 23 \\
\text { March } 26 \\
\text { March } 27 \\
\text { March } 29 \\
\text { March } 30 \\
\text { April } 2\end{array}$ & $\begin{array}{l}435 \\
501 \\
215 \\
553 \\
494 \\
655 \\
441 \\
375 \\
624 \\
398 \\
641 \\
369 \\
539 \\
450\end{array}$ & $\begin{array}{l}= \\
= \\
= \\
= \\
= \\
=\end{array}$ & $\begin{array}{l}4.49 \\
4.39 \\
4.48 \\
4.47 \\
4.33 \\
4.50 \\
4.44 \\
5.00 \\
4.51 \\
4.57 \\
5.05 \\
5.03 \\
5.00 \\
4.49\end{array}$ & $\begin{array}{l}5.52 \\
6.05 \\
5.24 \\
6.14 \\
5.55 \\
6.20 \\
5.53 \\
6.05 \\
6.23 \\
5.59 \\
6.40 \\
6.01 \\
6.25 \\
5.56\end{array}$ & $\begin{array}{l}63 \\
86 \\
36 \\
87 \\
82 \\
90 \\
69 \\
65 \\
92 \\
62 \\
95 \\
58 \\
85 \\
67\end{array}$ & $\begin{array}{l}399 \\
281 \\
201 \\
510 \\
459 \\
420 \\
416 \\
374 \\
463 \\
278 \\
535 \\
221 \\
478 \\
\text { San }\end{array}$ & $\begin{array}{r}147 \\
99 \\
68 \\
157 \\
149 \\
164 \\
147 \\
137 \\
162 \\
106 \\
133 \\
98 \\
140\end{array}$ & $\begin{array}{c}4.51 \\
4.36 \\
4.46 \\
4.50 \\
4.27 \\
4.58 \\
4.57 \\
4.57 \\
4.53 \\
5.06 \\
5.12 \\
5.10 \\
5.07 \\
4.57 \\
- \text { Sampler da }\end{array}$ & $\begin{array}{c}6.01 \\
6.03 \\
5.17 \\
6.07 \\
5.49 \\
6.17 \\
6.04 \\
5.45 \\
6.15 \\
5.51 \\
6.30 \\
5.55 \\
6.17 \\
\text { Imaged by }\end{array}$ & $\begin{array}{r}70 \\
87 \\
31 \\
77 \\
82 \\
79 \\
67 \\
48 \\
82 \\
45 \\
78 \\
45 \\
70 \\
\\
\quad-\end{array}$ \\
\hline Totals & 6,690 & 0 & & & 1,037 & 5,035 & 1,707 & & & 861 \\
\hline
\end{tabular}


determined by observation of the fluorescence of the condensed liquid in the thimble section. When illumination with an ultraviolet lamp showed this liquid to be free from fluorescent material, the extraction was stopped and all but about $10 \mathrm{ml}$. of the acetone removed by distillation. The extract was then evaporated on a constant temperature water-bath at $65^{\circ} \mathrm{C}$. to $3 \mathrm{ml}$., when $2 \mathrm{ml}$. of cyclohexane was added and the residue evaporated to about $2.5 \mathrm{ml}$.

The sample was transferred to the top of a $12 \times \frac{1}{2}$ in. $(30.48 \times 1.27 \mathrm{~cm}$.) diameter, 100 to 200 mesh activated alumina column, using a long glass capillary tube fitted with a rubber suction bulb. The alumina contained about $13 \%$ moisture. To prevent the column from being disturbed by eluant, two or three circles cut from glass fibre pad were inserted gently on the top of the column and these were followed by several loose strands of etherwashed 'glass wool'.

Cyclohexane, the main eluant, was run into the column from a cylindrical separating funnel. After the first 12 samples, gradually increasing quantities of diethyl ether were added to the cyclohexane, up to a maximum of $10 \%$, the rate of addition being determined by the clarity of elution of the various bands down the column. Passage of these bands was followed with a $3650 \AA$ ultraviolet lamp, but the time of illumination was limited to about five seconds each time to reduce the possibility of decomposition.

The samples, each of $25 \mathrm{ml}$., were collected in brown phials attached to a fraction collector turn-table and evaporated on the low temperature water-bath to decrease the ether content to $1 \%$. The spectra of the fractions were then recorded separately on a Beckman DK-2 ratio recording spectrophotometer.

Quantitative measurements were made using the Beer-Bouguer law of linear concentration/absorbance dependence and a local base line technique, essentially that of Cooper (1954). The reference absorption of the standard graph was measured for the identical base line as the fraction being examined. Some mixing occurred between polycyclic compounds adsorbed to about the same amount, but this was resolved by two component techniques.

Photographs of the spectra of individual air particulate fractions are shown in Figs. 1 to 5, and superimposed on these are spectra of the corresponding pure compounds which are shown as a broken line. The range of wavelength values 210 to $440 \mathrm{~m} \mu$ was usually taken. A cam change occurs on the Beckman DK-2 spectrophotometer at about $360 \mathrm{~m} \mu$, the wave-length scale after the change recommencing at $320 \mathrm{~m} \mu$. Both scales are linear; the region 320 to $440 \mathrm{~m} \mu$ may, however, be magnified by changing a gear ratio. This magnified scale is shown in Fig. 5 for 3,4-benzpyrene.

More detailed analysis of a typical air particulate sample, using the method and techniques described here, has been given by one of us (Cleary, 1962).

\section{Results}

The results of the analyses at each of the three test locations are given in Tables 2 and 3 . Table 4 gives the details of smoke stain samples, total particulates, and concentrations of total solids at the three sampling sites. In Sydney, at least two-thirds of the total atmospheric particulate loading is in the larger size ranges which, it has been shown (Sullivan, 1962), can be removed without producing any difference in the density of smoke stains on filter-paper samples. Smoke stain filter-paper samples were not collected systematically during the investigation, but the means obtained from runs made on some of the days calculated from the relation used by the D.S.I.R. Great Britain are shown in Table 4. The very considerable discrepancy between the calculated value of particulate density from the smoke stain reading and the measured concentration appears to be due to the formula used for the calculation and lends emphasis to the often repeated injunction that it is only suitable for a limited set of conditions.

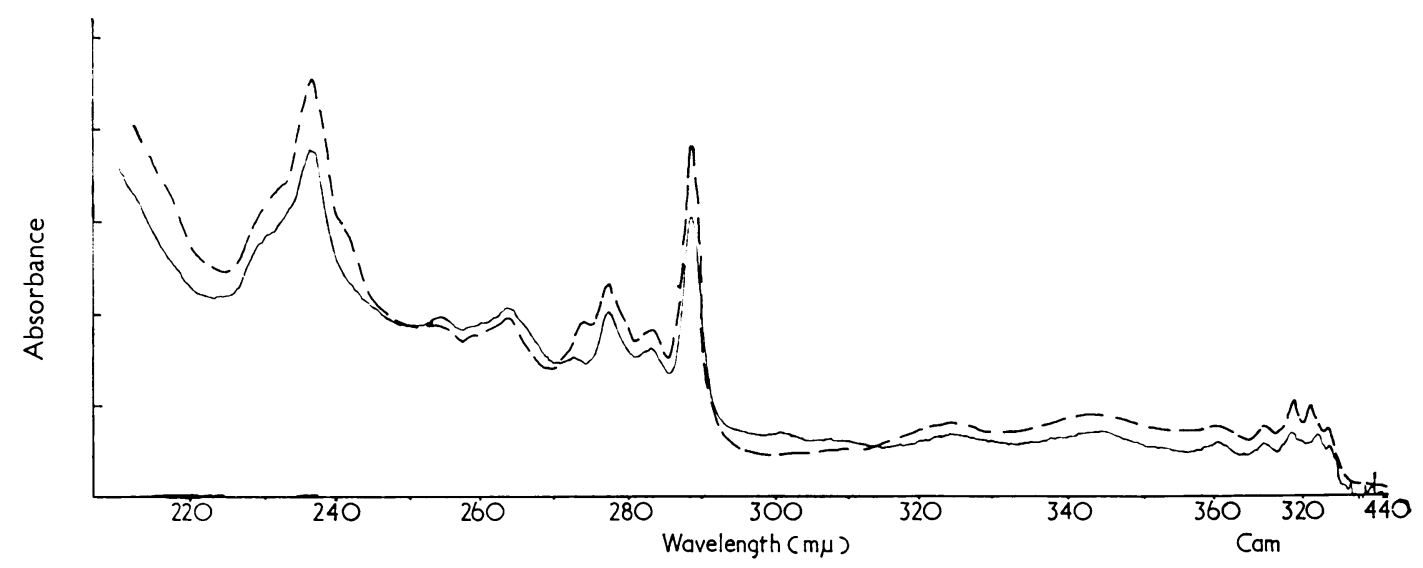

Fig. 1.-Air particulate fraction (-); pure fluoranthene (- . - -). 


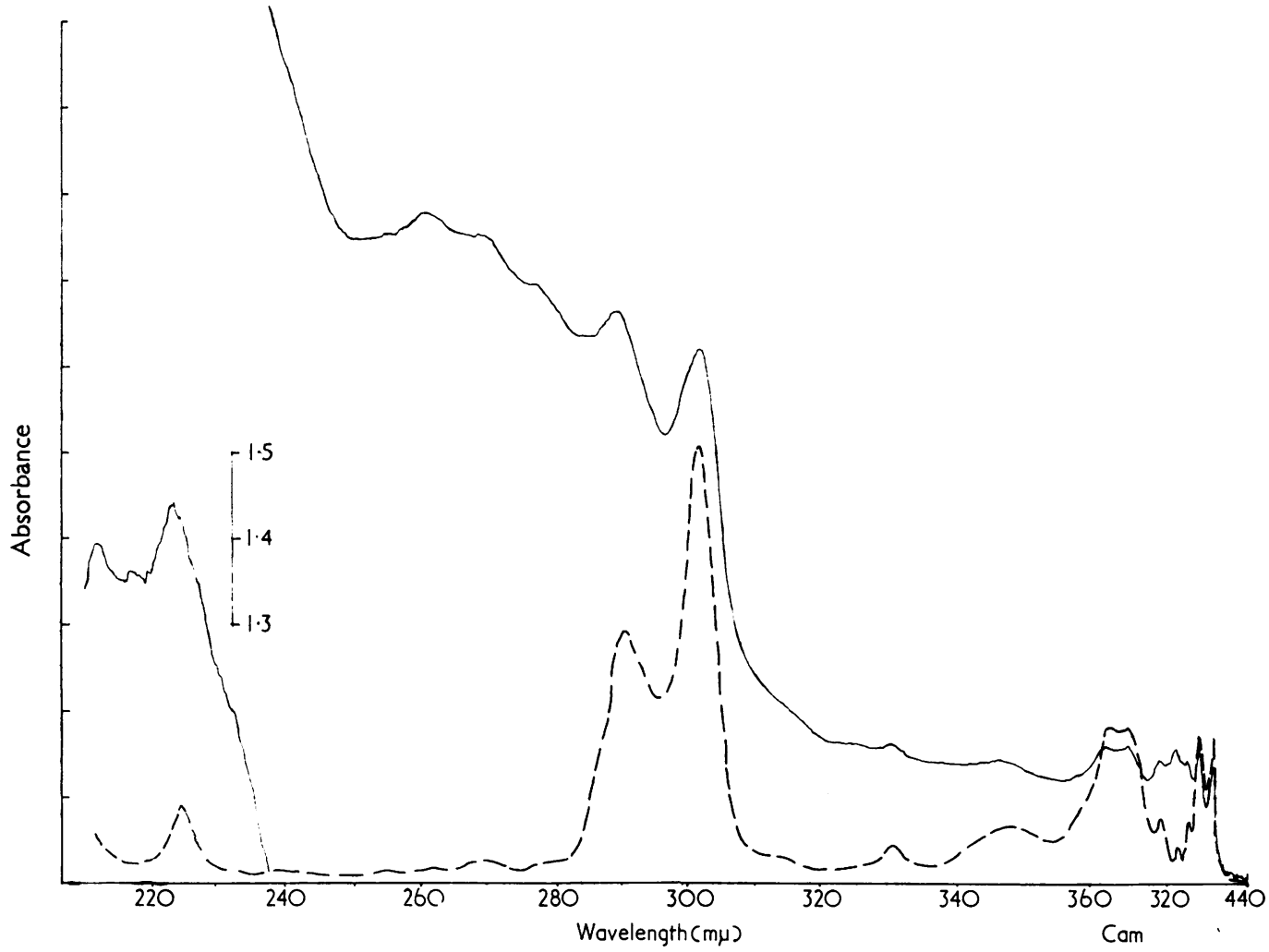

Fig. 2.-Air particulate fraction (-); pure 1,12-benzperylene (- . - -).

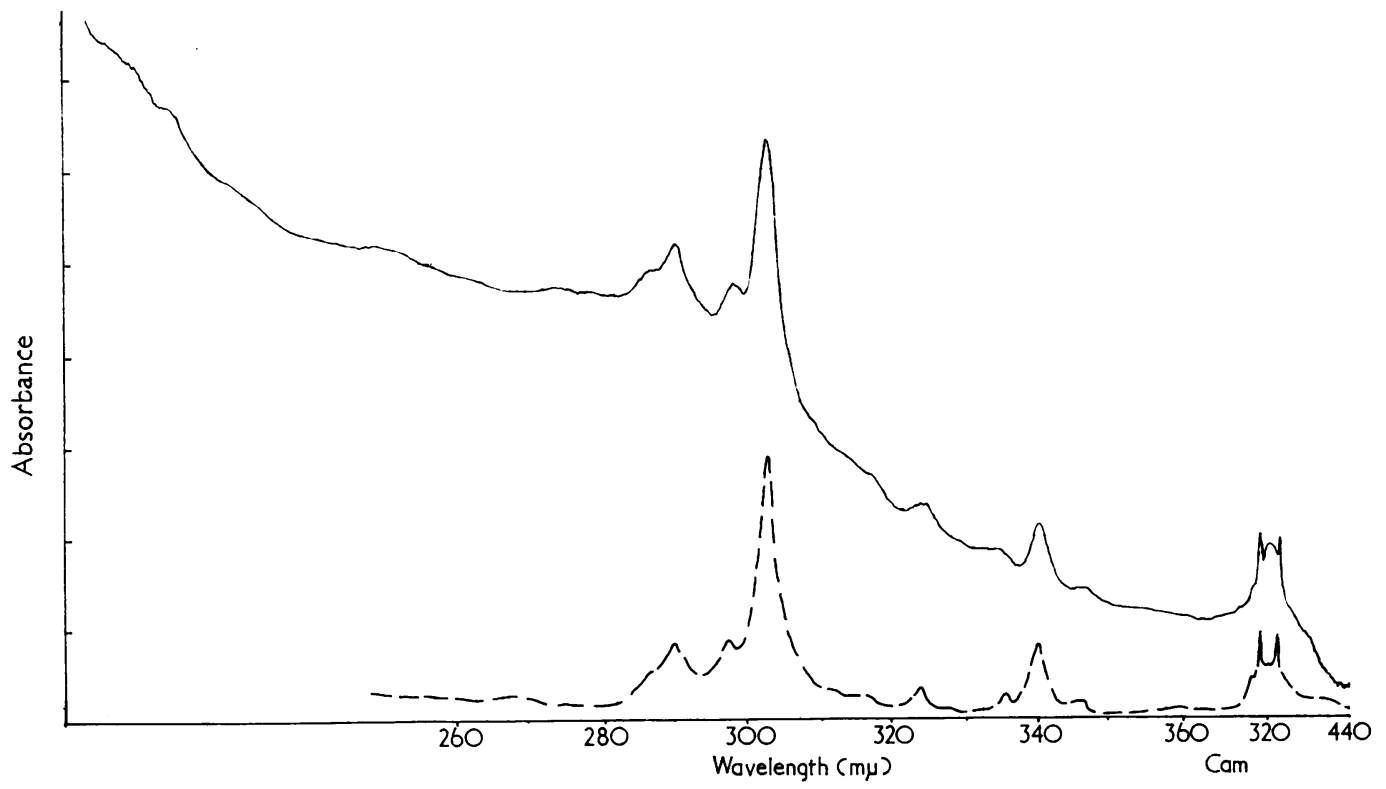

FIG. 3.-Air particulate fraction (-); pure coronene (- . - -). 


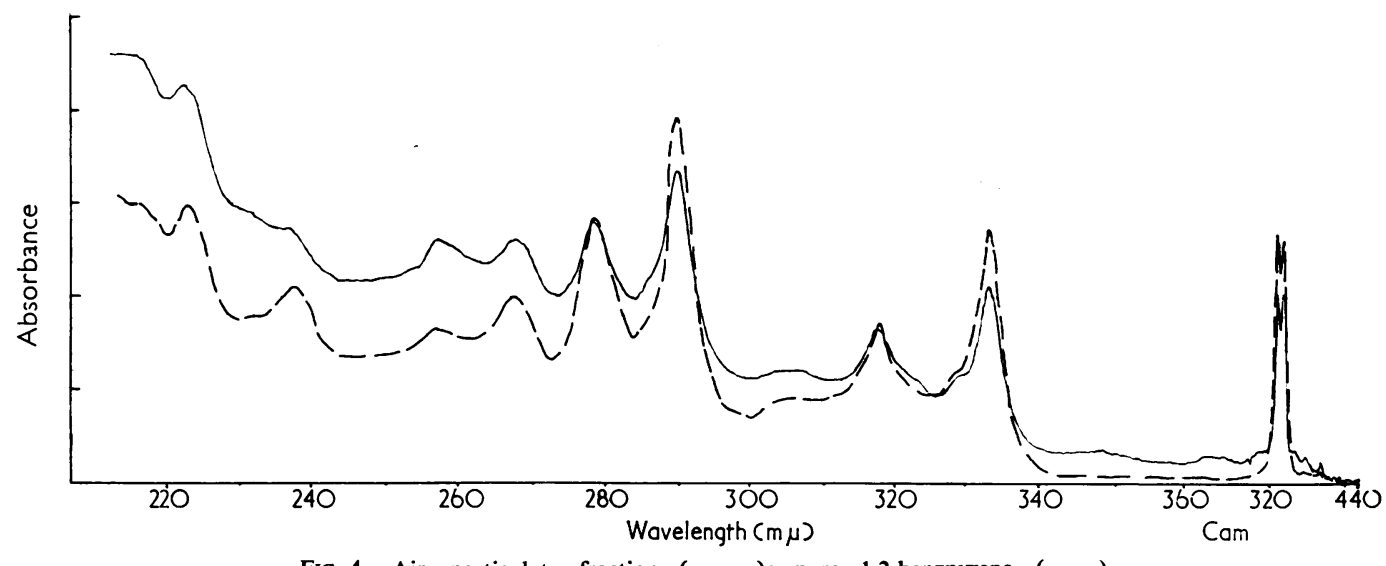

Fig. 4.-Air particulate fraction (-); pure 1,2-benzpyrene (- - -).

Fig. 5.-Air particulate fraction (- - ); pure 3,4-benzpyrene (-..).

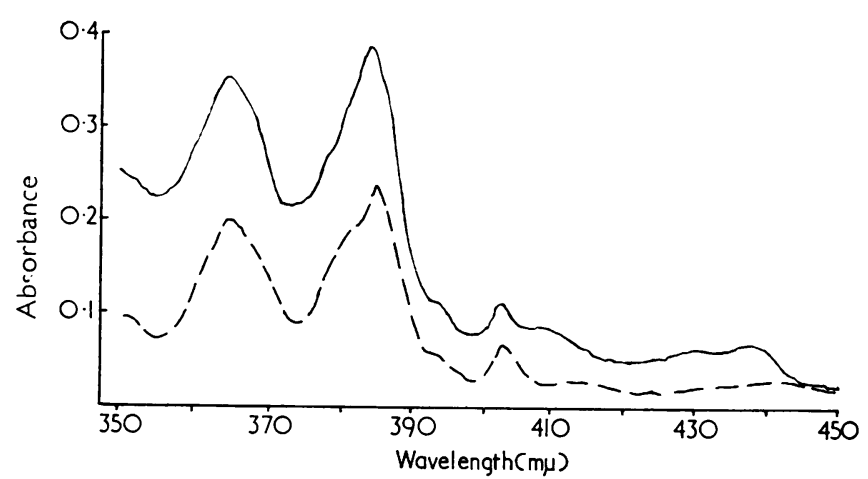

TABLE 2

CONCENTRATION OF POLYCYCLIC HYDROCARBONS AS PARTS PER MILLION OF SUSPENDED MATTER COLLECTED

\begin{tabular}{l|c|c|c}
\hline \multicolumn{1}{c|}{ Compound } & Diesel Lane & Petrol Lane & Background \\
\hline Pyrene & 122 & 227 & 38.6 \\
Fluoranthene & 86.5 & 61.3 & 29.7 \\
1,2-Benzanthracene & 32.4 & 31.2 & 10.1 \\
Chrysene & 11.1 & 22.0 & 12.6 \\
3,4-Benzpyrene & 83.5 & 29.4 & 14.7 \\
1,2-Benzpyrene & 50.7 & 23.3 & 14.0 \\
1,12-Benzperylene & 88.5 & 48.0 & 34.1 \\
Coronene & 92.9 & 53.9 & 33.9 \\
\hline
\end{tabular}

TABLE 3

CONCENTRATION OF POLYCYCLIC HYDROCARBONS AS MICROGRAMMES PER 1,000 CUBIC METRES OF AIR SAMPLED

\begin{tabular}{l|c|c|c}
\hline \multicolumn{1}{c|}{ Compound } & Diesel Lane & Petrol Lane & Background \\
\hline Pyrene & 35.2 & 35.4 & $5 \cdot 8$ \\
Fluoranthene & 25.2 & 9.5 & 4.4 \\
1,2-Benzanthracene & $9 \cdot 4$ & 4.9 & 1.5 \\
Chrysene & 3.2 & 3.4 & 1.9 \\
3,4-Benzpyrene & 24.2 & 4.6 & $2 \cdot 2$ \\
1,2-Benzpyrene & 14.7 & 3.6 & $2 \cdot 1$ \\
1,12-Benzperylene & 25.7 & 7.6 & 5.1 \\
Coronene & 26.9 & 8.4 & 5.1 \\
\hline
\end{tabular}


TABLE 4

SMOKE DENSITIES BASED ON WEIGHT OF DEPOSIT AND CONVERSION FROM PHOTOELECTRIC MEASUREMENT (mg./m..$\left.^{3}\right)$

\begin{tabular}{|c|c|c|c|c|c|}
\hline \multicolumn{2}{|c|}{ Diesel Laine } & \multicolumn{2}{|c|}{ Petrol Lane } & \multicolumn{2}{|c|}{ Background } \\
\hline Weighed Sample Pads & D.S.I.R. Conversion & Weighed Sample Pads & D.S.I.R. Conversion & Weighed Sample Pads & D.S.I.R. Conversion \\
\hline $0 \cdot 289$ & 0.640 & $0 \cdot 156$ & 0.081 & $0 \cdot 149$ & 0.060 \\
\hline
\end{tabular}

TABLE 5

RELATIVE CONTRIBUTION OF DIESEL AND PETROL VEHICLES

\begin{tabular}{|c|c|c|c|c|c|}
\hline \multirow[b]{2}{*}{ Compound } & \multicolumn{3}{|c|}{ Concentrations } & \multirow{2}{*}{$\begin{array}{c}\text { Estimated } \\
\text { Concentrations in } \\
\text { Diesel Lane for } \\
\text { Exhaust Volume } \\
\text { Equivalent to Lane } \\
\text { containing Petrol } \\
\text { Vehicles only } \\
\left(\mu \mathrm{g} . / 1000 \mathrm{~m}^{3}\right)\end{array}$} & \multirow[b]{2}{*}{$\begin{array}{l}\text { Ratio Diesel Lane } \\
\text { to Petrol Lane } \\
\text { Concentrations for } \\
\text { Equal Exhaust } \\
\text { Volume } \\
\left(\mu \mathrm{g} . / 1000 \mathrm{~m}^{\mathrm{s}}\right)\end{array}$} \\
\hline & $\begin{array}{c}\text { In Lane without } \\
\text { Diesel Vehicles } \\
\text { minus Atmospheric } \\
\text { Background } \\
\left(\mu \mathrm{g} . / 1000 \mathrm{~m} .^{3}\right)\end{array}$ & $\begin{array}{l}\text { In Lane containing } \\
\text { Diesel and Petrol } \\
\text { Vehicles minus } \\
\text { Atmospheric } \\
\text { Background } \\
\left(\mu \mathrm{g} / 1000 \mathrm{~m}^{3}\right)\end{array}$ & $\begin{array}{c}\text { In Lane containing } \\
\text { Diesel Vehicles minus } \\
\text { Petrol Vehicles } \\
\text { Contribution in } \\
\text { that Lane } \\
\left(\mu \mathrm{g} / 1000 \mathrm{~m} .^{3}\right)\end{array}$ & & \\
\hline $\begin{array}{l}\text { Pyrene } \\
\text { Fluoranthene } \\
\text { 1,2-Benzanthracene } \\
\text { Chrysene } \\
\text { 3,4-Benzpyrene } \\
\text { 1,2-Benzpyrene } \\
\text { 1,12-Benzperylene } \\
\text { Coronene }\end{array}$ & $\begin{array}{r}29 \cdot 6 \\
5 \cdot 1 \\
3 \cdot 4 \\
1 \cdot 5 \\
2 \cdot 4 \\
1 \cdot 5 \\
2 \cdot 5 \\
3 \cdot 3\end{array}$ & $\begin{array}{r}29 \cdot 4 \\
20 \cdot 8 \\
7 \cdot 9 \\
1 \cdot 3 \\
22 \cdot 0 \\
12 \cdot 6 \\
20 \cdot 6 \\
21 \cdot 8\end{array}$ & $\begin{array}{r}7 \cdot 1 \\
17 \cdot 0 \\
5 \cdot 3 \\
0 \cdot 2 \\
20 \cdot 2 \\
11 \cdot 5 \\
18 \cdot 7 \\
19 \cdot 3\end{array}$ & $\begin{array}{r}3 \cdot 6 \\
8 \cdot 6 \\
2 \cdot 7 \\
0 \cdot 1 \\
10 \cdot 2 \\
5 \cdot 8 \\
9 \cdot 4 \\
9 \cdot 7\end{array}$ & $\begin{array}{l}0 \cdot 12 \\
1 \cdot 7 \\
0 \cdot 79 \\
0 \cdot 07 \\
4 \cdot 2 \\
3 \cdot 9 \\
3 \cdot 8 \\
2 \cdot 9\end{array}$ \\
\hline
\end{tabular}

gases at that time. To reach an exhaust gas volume basis for comparison, the general atmospheric background of polycyclic hydrocarbon concentration was first subtracted from the result in each vehicle lane. Then the equivalent contributions made by the petrol vehicles which used the diesel lane were extrapolated from the results obtained in the petrol lane and subtracted from the total polycyclic hydrocarbon concentrations. These corrected results are presented in columns 1,2 , and 3 of Table 5 . Column 3 purports to show the likely concentrations of polycyclic hydrocarbons which could be attributed only to the diesel vehicles in the lane.

The next column of the table shows the concentrations in terms of the volume of exhaust gases discharged, as determined from the relative numbers of the two vehicle types and the differences in engine capacities. It was found that almost exactly twice the total volume of exhaust gases was discharged by the diesel vehicles as by the motor-cars in the lane without diesel vehicles, and therefore the results for column 4 were obtained simply by halving those in column 3. In short, the purpose was to estimate what the concentrations might have been in the lane carrying diesel vehicles if the quantity of exhaust gases discharged there had been the same as in the lane not carrying diesels.

The last column in the table, which was obtained by dividing the results shown in column 4 by column 1 , shows the ratios of the various hydrocarbon concentrations obtained on the basis of the discharge of equal volumes. This is presented to show the differences between the various members emitted by the two types of engine. The most striking observation was that the concentration of the higher molecular weight groups was greater in the lane carrying diesel engines whereas for the lower molecular weight compounds the ratios, with the one exception of fluoranthene, were reversed.

\section{Discussion}

The special circumstance of Sydney's traffic resulting in one area of virtually complete segregation of diesel-powered vehicles is probably unique. Thus, the tests for polycyclic hydrocarbons were done in what was essentially a normal traffic situation in a congested city street in the vicinity of motor vehicles which were in all probability in an average state of maintenance. In the latter regard, the diesel vehicles which passed the test area are nearly all owned and operated by one organization which has a regular maintenance programme and adequate workshop facilities.

It would be difficult to account for the differences between the traffic lane carrying diesel vehicles and the one that was not, other than on the basis of the rates of emission of polycyclic hydrocarbons. In both cases, the vehicles discharged exhaust gases near to road level, but the exhaust pipes on the diesel vehicles were located in such a manner as to cause gases to be discharged towards the ground and from the side of the vehicle near the rear. As this was also the side on which the sampler was located it is possible that this could partially explain the difference in polycyclic hydrocarbon concentrations 
found. However, the sampler was located about - 6 feet $(1.828 \mathrm{~m}$.) above ground level, and from observations at the time it appeared that the visible smoke was dispersing in the atmosphere generally. There was no evidence of any special accumulation in the vicinity of the sampler.

We can offer no explanation for the fact that the ratios shown in Table 5 for five- and six-ring hydrocarbon concentrations were greater than one in the area exposed to diesel emissions but less than one for the four-ring compounds. It appears to be that the higher molecular weight hydrocarbons occur in greater concentrations when the smoke density is higher, but there is not a similarly associ- ated relation with the lower molecular weight compounds.

One of us (G.J.C.) gratefully acknowledges the sponsorship of the Atmospheric Pollution Management Committee, New South Wales.

\section{REFERENCES}

Cleary, G. J. (1962). J. Chromatog., 9, 204.

Commins, B. T., Waller, R. E., and Lawther, P. J. (1957). Brit. J. industr. Med., 14, 232

Cooper, R. L. (1954). Analyst, 79, 573.

Kotin, P., Falk, H. L., and Thomas, M. (1955). A.M.A. Arch. industr. Hyg., 11, 113

Moore, G. E., and Katz, M. (1960). Int. J. Air Poll., 2, 221.

Sullivan, J. L. (1962). J. Air Pollution Control Ass., 12, 474. Waller, R. E., Commins, B. T., and Lawther, P. J. (1961). Brit. J.
industr. Med., 18, 250 . 